\title{
SHP2 inhibitor PHPS1 protects against atherosclerosis by inhibiting smooth muscle cell proliferation
}

\author{
Jia Chen ${ }^{1}$, Zhiyong Cao $^{2}$ and Jingshu Guan ${ }^{1 *}$ (D)
}

\begin{abstract}
Background: Smooth muscle cells play an important role in the development of atherosclerosis. SHP2 is known to regulate the proliferation and migration of smooth muscle cells. The purpose of this study was to determine whether the SHP2 inhibitor PHPS1 has a pro-atherosclerotic or an atheroprotective effect in vivo and in vitro.

Methods: After exposure to a high-cholesterol diet for 4 weeks, LDL receptor-deficient $\left(\mathrm{Ldlr}^{-/-}\right)$mice were exposed to the SHP2 inhibitor PHPS1 or vehicle. Body weight, serum glucose and lipid levels were determined. The size and composition of atherosclerotic plaques were measured by en face analysis, Movat staining and immunohistochemistry. The phosphorylation of SHP2 and related signaling molecules was analyzed by Western blot. Mechanistic analyses were performed in oxLDL-stimulated cultured vascular smooth muscle cells (VSMCs) with or without $10 \mathrm{mM}$ PHPS1 pretreatment. Protein phosphorylation levels were detected by Western blot, and VSMC proliferation was assessed by BrdU staining.

Results: PHPS1 decreased the number of atherosclerotic plaques without significantly affecting body weight, serum glucose levels or lipid metabolism. Plaque composition analysis showed a significant decrease in the number of VSMCS in atherosclerotic lesions of $\mathrm{Ldlr}^{-1-}$ mice treated with PHPS1. Stimulation with oxLDL induced a dose-dependent increase in the number of VSMCS and in SHP2 and ERK phosphorylation levels, and these effects were blocked by PHPS1.
\end{abstract}

Conclusion: The SHP2 inhibitor PHPS1 exerts a protective effect against atherosclerosis by reducing VSMC proliferation via SHP2/ERK pathway activation.

Keywords: SHP2, PHPS1, Atherosclerosis, Smooth muscle cells, Proliferation, ERK

\section{Background}

Cardiovascular disease is a threat to human health and seriously impacts quality of life [1]. Atherosclerosis (AS) is a major pathological basis of cardiovascular and cerebrovascular diseases [2]. Although the mechanism underlying AS is complex, the basic pathology of AS is fibrous proliferation caused by the presence of progressive lipid deposits, accumulation of inflammatory cells and deposition of extracellular matrix $[3,4]$. AS is not a separate pathological process; rather, it is regulated by a variety of cells

\footnotetext{
* Correspondence: guanjingshu@yeah.net

${ }^{1}$ Department of Cardiology, Shanghai Baoshan Hospital of Integrated Traditional Chinese and Western Medicine, Friendship Road 181, Baoshan District, Shanghai, China

Full list of author information is available at the end of the article
}

and intracellular signaling pathways [5]. Smooth muscle cells (SMCs) play an important role in the development of AS $[6,7]$.

Protein tyrosine phosphorylation and dephosphorylation play significant roles in numerous intracellular signaling pathways and are influenced by several opposing kinases, such as protein tyrosine kinases (PTKs) and protein tyrosine phosphatases (PTPs) $[8,9]$. PTKs catalyze tyrosine phosphorylation, whereas PTPs catalyze dephosphorylation [10]. Src homology 2 domain-containing protein tyrosine phosphatase 2 (SHP2), also known as protein tyrosine phosphatase N 11 (PTPN11), is an important PTP that acts downstream of various growth factors, cytokines and tyrosine kinases. It plays an integral role in multiple cellular

(C) The Author(s). 2018 Open Access This article is distributed under the terms of the Creative Commons Attribution 4.0 International License (http://creativecommons.org/licenses/by/4.0/), which permits unrestricted use, distribution, and 
events that regulate various functions, including migration, differentiation, survival and metabolism [11-13]. Schramm found that pharmacological reduction of SHP2/FAK/ Akt/mTOR signaling at all levels of the signaling cascade effectively prevents cardiomyocyte hypertrophy [14]. In recent years, SHP2 inhibitors have become available for research applications. A SHP2 inhibitor phenylhydrazono pyrazolone sulfonate 1 (PHPS1) is a potent and cell permeable inhibitor that is specific for SHP2 over the closely related tyrosine phosphatases SHP1 and PTP1B [15]. In neutrophils, inflammatory monocytes and pDCs, the level of SHP2 expression is much lower than SHP1 [16]. PTP1B is an enzyme that negatively regulates insulin signaling and is likely involved in the pathways leading to insulin resistance [17]. PHPS1 remarkably suppresses E2-induced gene transcription, rapid DNA synthesis and late effects on cell growth. The finding introduces a new mechanism for SHP2 oncogenic action and sheds new light on extranuclear ER-initiated actions in breast cancer [18]. SHP2 regulates the acute pulmonary inflammation induced by cigarette smoke through the ERK1/2 pathway. PHPS1 significantly inhibits ERK1/2 activation and attenuates the inflammatory response induced in mouse lungs [19].

The purpose of this study was to determine whether the SHP2 inhibitor PHPS1 has a pro-atherosclerotic or an atheroprotective effect in vivo and in vitro by evaluating the effect of phosphorylation or dephosphorylation on the development of AS in LDL receptor-deficient $\left(\mathrm{Ldlr}^{-/-}\right)$mice.

\section{Methods}

\section{Animal preparation}

$\mathrm{Ldlr}^{-1-}$ (005061) mice were purchased from Jackson Laboratory. All animal protocols were approved by the Ethics Committee for Animal Experimentation at the Second Military Medical University. Five mice were housed in a cage on a 12-h light/dark cycle with free access to water and food. The animals received a high-fat diet containing $1.25 \%$ cholesterol for 4 weeks. The SHP2 inhibitor PHPS1 was purchased from Sigma-Aldrich. PHPS1 was dissolved in saline with $0.5 \%$ DMSO. Thirty mice were randomly divided into three groups: an AS group, an AS+Vehicle group and an AS+PHPS1 group. Mice in the AS+PHPS1 group received an intraperitoneal (i.p.) injection of $3 \mathrm{mg} / \mathrm{kg}$ PHPS1 every day during the last week on the high-fat diet, and those in the AS + Vehicle group received an equal volume of saline with $0.5 \%$ DMSO on the same days.

\section{Measurement of serum glucose and lipids}

The mice were euthanized with an overdose of pentobarbital. Blood samples were collected in EP tubes containing $2 \mathrm{mM}$ EDTA and centrifuged $(13,000 \mathrm{~g})$ for $15 \mathrm{~min}$ at $4{ }^{\circ} \mathrm{C}$. Plasma aliquots were separated and stored at $-80{ }^{\circ} \mathrm{C}$. The serum glucose level was determined using the glucose oxidase method (Beckman). Levels of triglycerides (TG), total cholesterol (TC), lowdensity lipoprotein cholesterol (LDL-C) and high-density lipoprotein cholesterol (HDL-C) were determined by high-performance liquid chromatography (HPLC).

\section{AS quantification}

Quantification of AS in the heart and aorta was performed by staining. Briefly, the heart and aorta were perfused with phosphate-buffered saline (PBS) from the left ventricle and dissected from the aortic arch to the iliac bifurcation. The adventitia was carefully cleaned from the surrounding material. The aorta was sliced into sections, fixed in $4 \%$ paraformaldehyde for $48 \mathrm{~h}$, stained with Oil Red $\mathrm{O}$, incubated for $30 \mathrm{~min}$ at $37{ }^{\circ} \mathrm{C}$, and washed with PBS several times; the area of the atherosclerotic lesion was compared to the total area of the aorta using a dissection microscope and Adobe Photoshop software.

The heart was embedded in optimal cutting temperature (OCT) compound and frozen at $-80{ }^{\circ} \mathrm{C}$. Serial sections $(8 \mu \mathrm{m})$ were taken from the aortic sinus and valve region, and sections in which all three valve leaflets were visible were used for Movat staining.

\section{Western blot analysis}

Protein samples $(30 \mu \mathrm{g})$ from cultured cells or aortic specimens were electrophoresed on a $12 \%$ polyacrylamide gel by SDS-PAGE and blotted onto a nitrocellulose membrane. After being blocked with 5\% BSA for $2 \mathrm{~h}$ at room temperature, the membrane was incubated overnight at $4{ }^{\circ} \mathrm{C}$ with primary antibodies (PRS3901, M5670, SAB4500491, and SAB4502398; 1:1,000 dilution; Sigma-Aldrich), washed with TBST 3 times, incubated with anti-rabbit secondary antibody (1:5,000 dilution) for $1 \mathrm{~h}$ at room temperature and then washed with TBST 3 times.

\section{Cell culture}

Mouse aorta vascular smooth muscle cells (VSMCs) were purchased from ATCC. The cells were grown in 6well culture plates in RPMI 1640 supplemented with $10 \%$ FBS, penicillin and streptomycin at $37{ }^{\circ} \mathrm{C}$ in a humidified atmosphere of $5 \% \mathrm{CO}_{2}$. The medium was changed daily, and the cells were passaged after treatment with $0.05 \%$ trypsin-0.02\% EDTA solution. Cells at passage 5-8 were used in the subsequent experiments. Cells were confirmed as SMCs by their typical "hill-and-valley" morphological features and by the expression of smooth muscle $\alpha$-actin by immunofluorescence. Cells were made quiescent by a 48 -h incubation in RPMI 1640 medium containing $0.1 \%$ FBS. 


\section{Cytotoxicity assay}

Cells were seeded in 96-well culture plates at a concentration of $5 \times 10^{5}$ cells $/ \mathrm{ml} 24 \mathrm{~h}$ prior to experiments. The cultured cells were stimulated with $10 \mu \mathrm{M}$ PHPS1 or an equal volume of DMSO for 30 min and then with $100 \mu \mathrm{g} / \mathrm{ml}$ oxLDL for $48 \mathrm{~h}$. Then, cells were washed 3 times with PBS. To evaluate the cytotoxicity of PHPS1 and DMSO, the number of cells was determined using the thiazolyl blue (MTT) test. A $10-\mu$ l volume of $5 \mathrm{mg} /$ $\mathrm{ml}$ MTT was added to each well, and the plates were incubated for $4 \mathrm{~h}$ at $37{ }^{\circ} \mathrm{C}$. The medium was removed, and the formazan crystals inside the cells were dissolved in $200 \mu \mathrm{l}$ of DMSO. The absorbance of each well was measured at $450 \mathrm{~nm}$ on a microplate reader.

\section{BrdU incorporation assay}

5-Bromo-2'-deoxyuridine (BrdU) uptake by VSMCs was measured using a kit obtained from Amersham International. Quiescent cells at 70\% confluence in DMEM with $0.5 \%$ FBS were treated with different stimuli for $24 \mathrm{~h}$. BrdU $(1 \mu \mathrm{mol} / \mathrm{L})$ was added and co-cultivated with the cells for the last $3 \mathrm{~h}$ of the 24-h stimulation period. BrdU incorporation into the cells was quantified using the BrdU cell proliferation assay kit (Roche Diagnostics, Indianapolis, IN, USA). The cells were counted under a microscope using a hemocytometer as previously described [20]. BrdU-labeled and unlabeled SMCs were counted in each section. The proliferation index was calculated by dividing the number of BrdU-labeled cells by the number of unlabeled cells.

\section{Statistics}

All data are presented as the mean \pm SE. Differences between groups were assessed using Student's t-test or one-way analysis of variance for multiple comparisons. $P$ values $<0.05$ indicated statistical significance, and the significance levels are provided in the text.

\section{Results}

PHPS1 renders $\mathrm{LdIr}^{-/}$mice less susceptible to AS development

To determine the pro-atherosclerotic or anti-atherosclerotic role of PHPS1, we ascertained the effect of PHPS1 on the

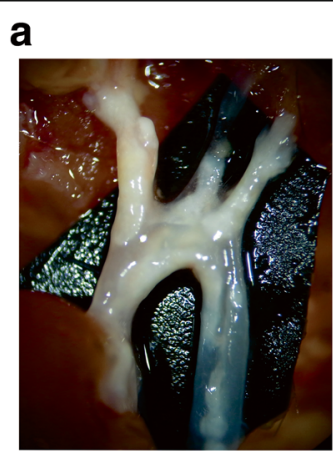

AS

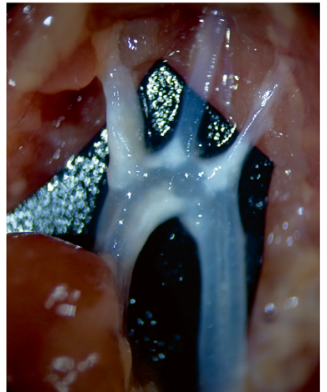

AS+PHPS1

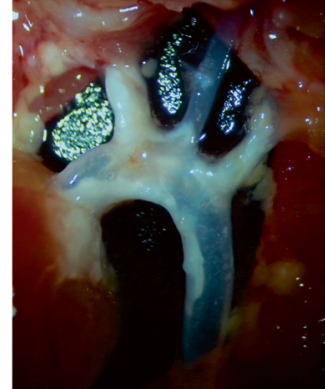

AS+Vehicle

b
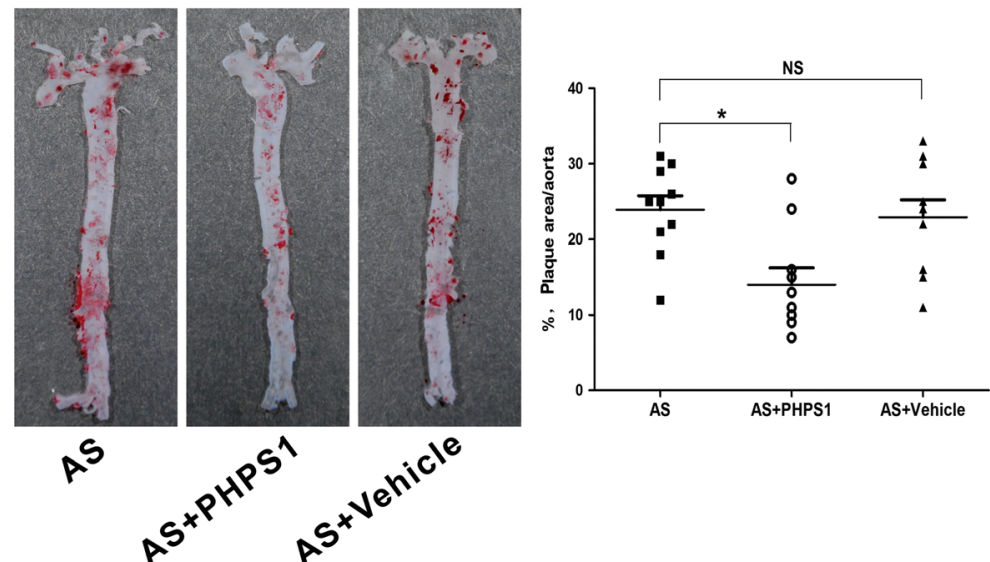

Fig. 1 The atherosclerotic plaque area was decreased in the AS+PHPS1 group. Ldlr ${ }^{-/-}$mice were fed a high-fat diet for 4 weeks. Mice in the AS +PHPS1 group were intraperitoneally injected with $3 \mathrm{mg} / \mathrm{kg}$ PHPS1 at the indicated time, and those in the AS+Vehicle group were injected with saline containing $0.5 \%$ DMSO. a Images of the aortic arch of Ldlr ${ }^{-1}$ mice in the AS, AS+PHPS1 and AS+Vehicle groups. $\mathbf{b}$ Left: representative en face images of the Oil Red O-stained whole aorta of $\mathrm{Ldlr}^{-/-}$mice. Right: quantification of the plaque area as a percentage of the aortic surface in $\mathrm{Ldlr}^{-/-}$mice. Data are presented as the mean $\pm \mathrm{SE}\left(n=10\right.$ per group). ${ }^{*} p<0.05$ vs. the AS group 
development and progression of AS in $\mathrm{Ldll}^{-/-}$mice. No significant differences in body weight or the levels of serum glucose, TC, TG, HDL-C or LDL-C were observed among the three groups (Additional file 1: Figure S1). Remarkably, en face analysis of the aorta stained with Oil Red $\mathrm{O}$ revealed a significant decrease in atherosclerotic plaque size in the aorta of the AS+PHPS1 group compared with the other two groups (Fig. 1). The atherosclerotic plaque area at the aortic root was significantly decreased in $\mathrm{Ldlr}^{-/-}$ mice treated with PHPS1. However, Movat staining showed no significant difference between the AS group and the Vehicle group. In the AS and AS+Vehicle groups, the intimal lesion was thicker, and both the vessel and lumen were narrowed. PHPS1 inhibited neointimal formation and SMC proliferation (Fig. 2).

\section{PHPS1 treatment inhibits the phosphorylation of SHP2 and ERK}

We analyzed the total and phosphorylated levels of JNK, p $38^{\mathrm{MAPK}}$ and ERK1/2 by Western blot. PHPS1 suppressed SHP2 and ERK phosphorylation without affecting JNK or p38 ${ }^{\mathrm{MAPK}}$ activation (Fig. 3), suggesting that PHPS1 might suppress P-SHP2 and P-ERK levels and consequently inhibit the progression of early lesions in $\mathrm{Ldlr}^{-/-}$mice.
Cytotoxic effects of PHPS1 on VSMCs in vitro

Because it was unknown whether PHPS1 is toxic to VSMCs, we treated cells with $10 \mu \mathrm{M}$ PHPS1 or an equal volume of DMSO for $30 \mathrm{~min}$. The doses of PHPS1 and DMSO used in the experiment were not toxic to the cells (Fig. 4).

\section{OxLDL induces ERK phosphorylation and activation and promotes VSMC proliferation}

VSMCs were incubated with $0,25,50$ or $100 \mu \mathrm{g} / \mathrm{ml}$ oxLDL for $10 \mathrm{~min}$. P-SHP2 and P-ERK levels were increased in the group treated with $25 \mu \mathrm{g} / \mathrm{ml}$ oxLDL compared with the control group and were highest in the $100 \mu \mathrm{g} / \mathrm{ml}$ group, revealing a concentration-dependent effect. The difference in total protein expression among groups was not statistically significant (Fig. 5a). The effect of oxLDL on VSMC proliferation was detected by the BrdU assay. As shown in Fig. 5b, stimulation with $100 \mu \mathrm{g} / \mathrm{mL}$ oxLDL for $24 \mathrm{~h}$ resulted in an approximate $50 \%$ increase in cell number, but that dose of oxLDL did not seem to affect VSMC proliferation to the same degree as $25 \mu \mathrm{g} / \mathrm{mL}$ oxLDL.

\section{PHPS1 inhibits oxLDL-induced ERK phosphorylation and VSMC proliferation}

Treatment of VSMCs with $100 \mu \mathrm{g} / \mathrm{ml}$ oxLDL increased the levels of phosphorylated SHP2 and ERK. PHPS1

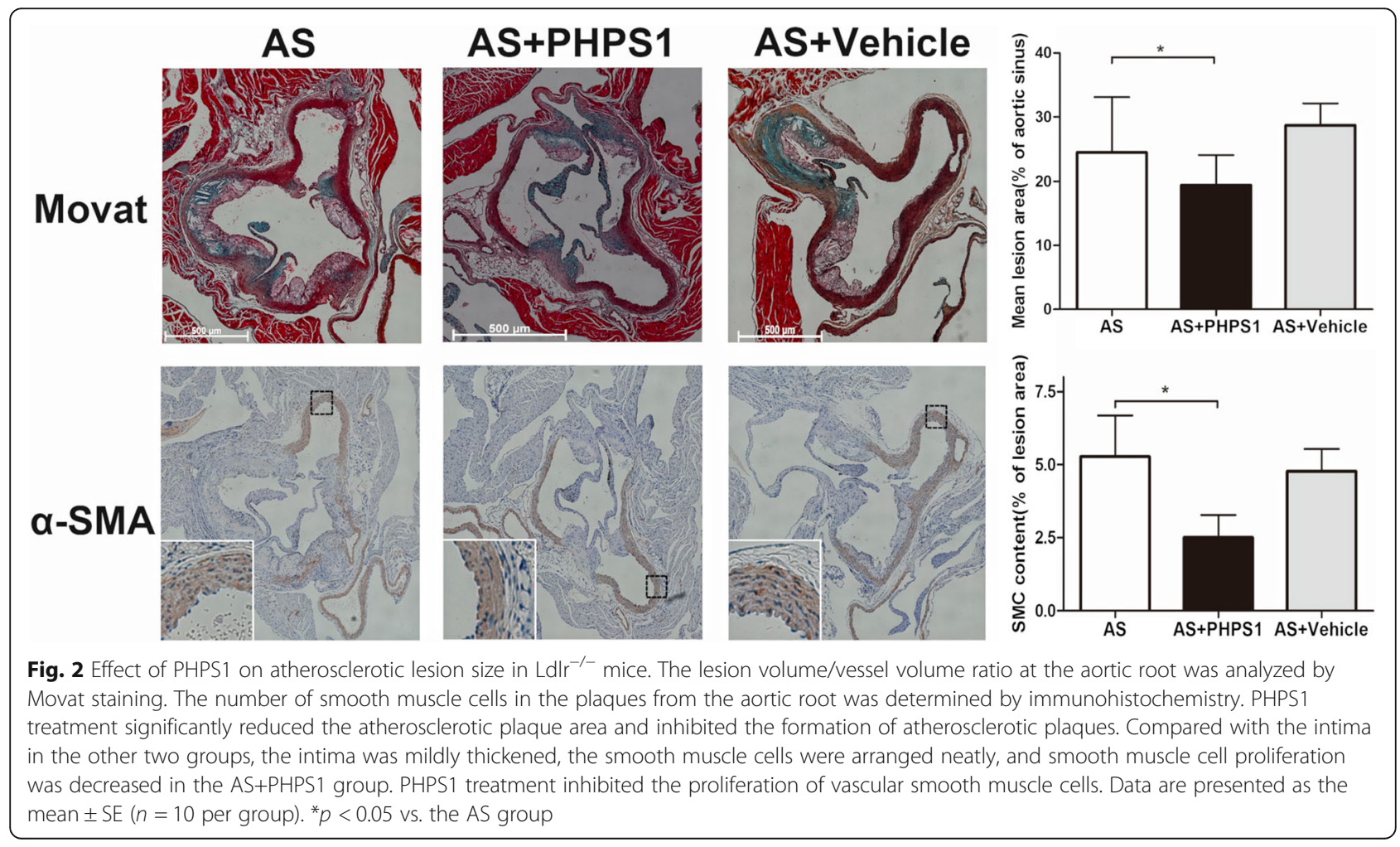



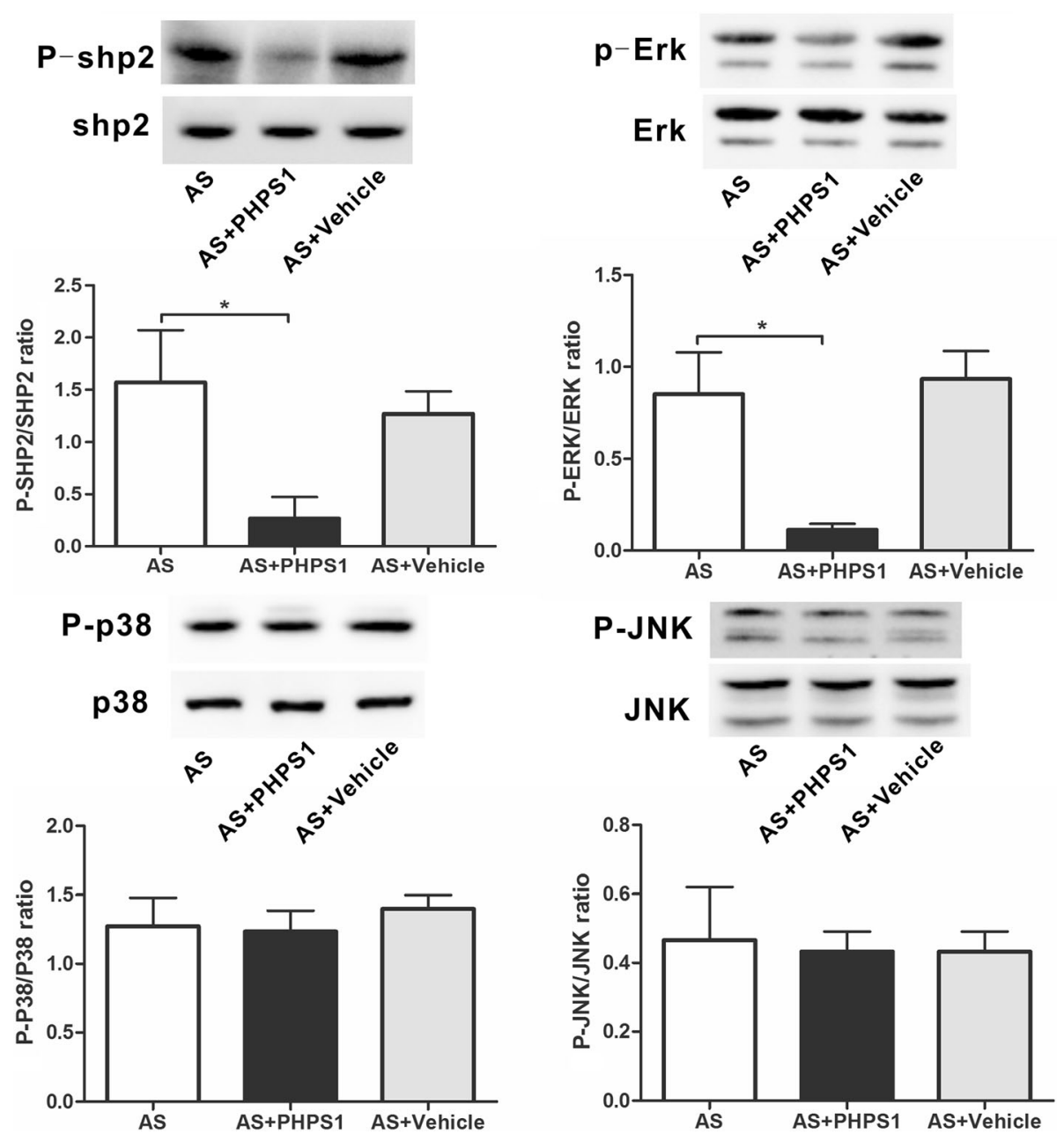

Fig. 3 The levels of total and phosphorylated SHP2, ERK, JNK and p38 were determined by Western blot analysis. There were no statistically significant differences in the total levels of SHP2, ERK, JNK or p38 ${ }^{\text {MAPK }}$ among the three groups $(p>0.05)$. PHPS1 suppressed the levels of phosphorylated SHP2 and ERK. Data are presented as the mean \pm SE. ${ }^{*} p<0.05$ vs. the AS group

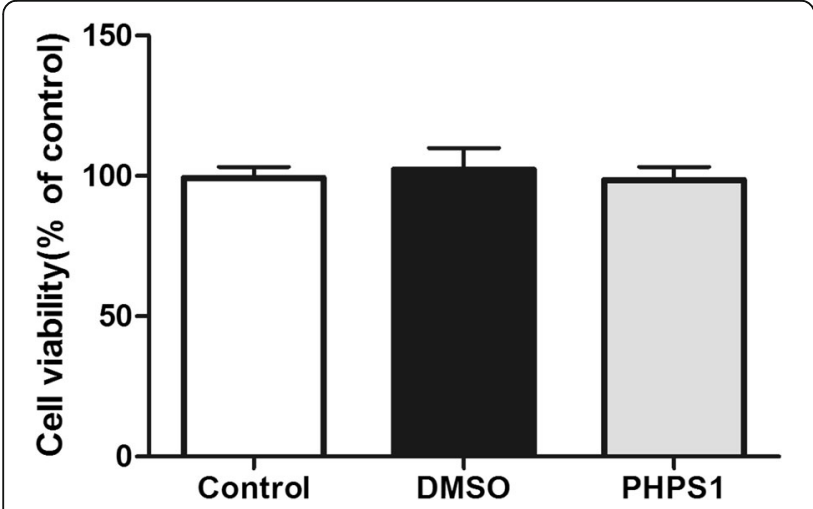

Fig. 4 Effects of DMSO and PHPS1 on the growth and viability of VSMCs. Cultured VSMCs were stimulated with $10 \mu \mathrm{M}$ PHPS1 or an equal volume of DMSO for $30 \mathrm{~min}$ and then with $100 \mu \mathrm{g} / \mathrm{ml} \mathrm{OxLDL}$ for $48 \mathrm{~h}$. Cell number and viability were determined by the MTT assay. Data are presented as the mean \pm SE. ${ }^{*} p<0.05$ vs. the control group attenuated P-SHP2 and P-ERK levels. In VSMCs, ERK phosphorylation was markedly inhibited after a $10-\mathrm{min}$ treatment with $10 \mu \mathrm{M}$ PHPS1. Treatment with DMSO did not affect P-SHP2 and P-ERK levels compared with control treatment (Fig. 6a). These results suggested that PHPS1 could inhibit oxLDL-induced SHP2-ERK signaling. As shown in Fig. 6b, VSMC proliferation was inhibited by PHPS1. Moreover, pretreatment with PHPS1 reversed the reinforcing effect of oxLDL on VSMC proliferation.

\section{Discussion}

This study showed that inhibiting the tyrosine phosphatase SHP2 with PHPS1 prevented the development of AS by inhibiting VSMC proliferation. This finding may provide a better understanding of the novel biological role of the SHP2 enzyme in the pathogenesis of AS. 
a
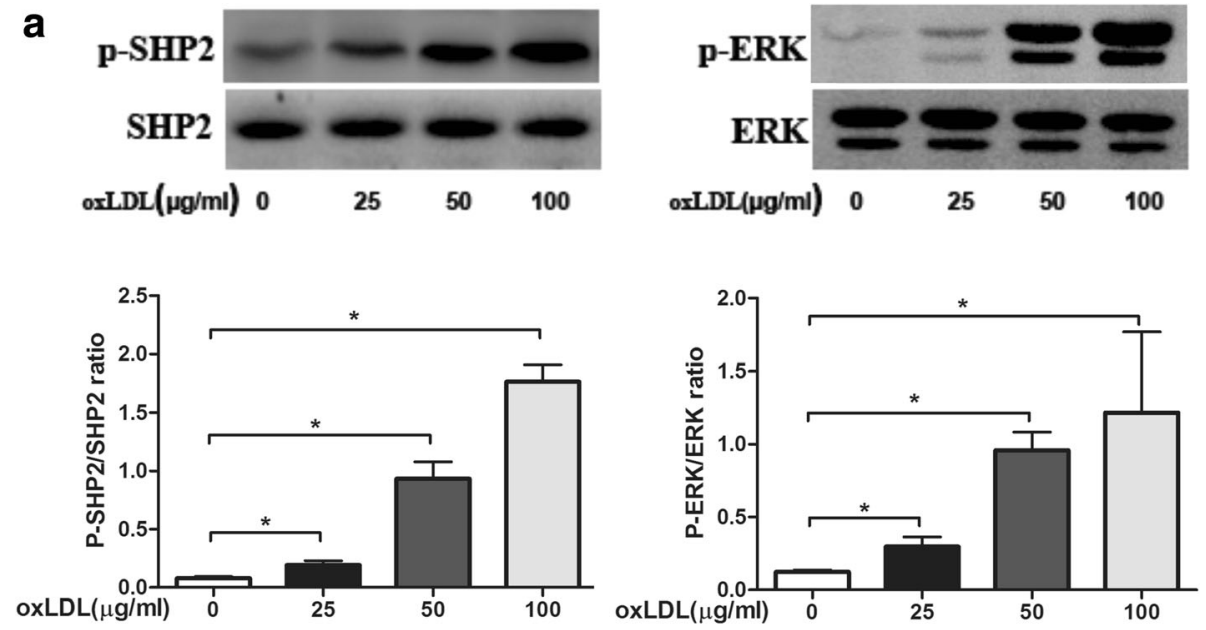

b

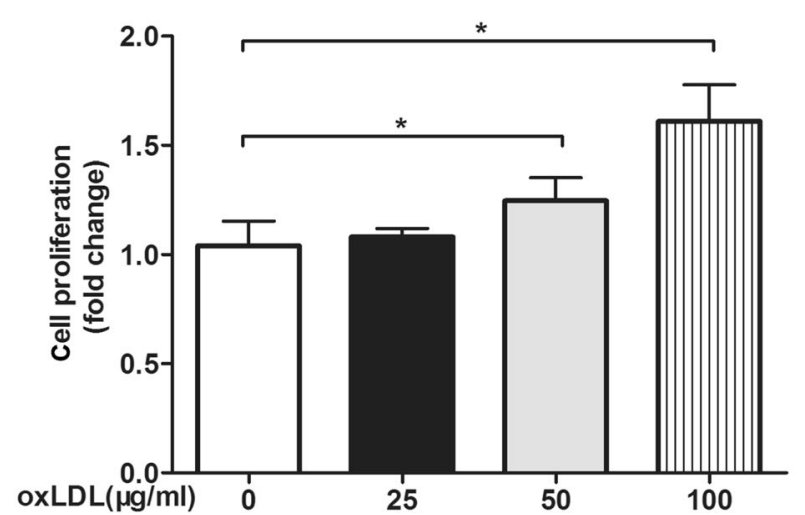

Fig. 5 a Quiescent cells were treated with different concentrations $(0,25,50$ or $100 \mu \mathrm{g} / \mathrm{ml}$ ) of oxLDL for $10 \mathrm{~min}$. Treatment was terminated by washing the cells with ice-cold PBS. Cells were lysed in $100 \mu \mathrm{l}$ of lysis buffer containing protease and phosphatase inhibitor cocktails. Protein content in the samples was determined using the bicinchoninic acid assay, and the samples were heated at $100{ }^{\circ} \mathrm{C}$ in $5 \times$ protein loading dye for 5 min. Equal amounts of protein were separated by SDS-polyacrylamide gel electrophoresis, transferred to a polyvinylidene fluoride membrane and probed with monoclonal antibodies against total and phosphorylated SHP2 and ERK1/2. OxLDL activated SHP2 in a concentration-dependent manner. Total SHP2, phosphorylated SHP2, total ERK and phosphorylated ERK levels were examined by Western blot. Relative quantification of target proteins was performed by comparing band density levels among samples. The results are reported as the mean $\pm \mathrm{SE}\left(n=3\right.$ per group). ${ }^{*} p<0.05 \mathrm{vs}$. the no-oxLDL treatment group. $\mathbf{b}$ Effects of SHP2 on VSMC proliferation. Smooth muscle cells were exposed to different concentrations $(0,25,50 \mathrm{or} 100 \mu \mathrm{g} / \mathrm{ml})$ of oxLDL for $24 \mathrm{~h}$. BrdU (1 $\mu \mathrm{mol} / \mathrm{L})$ was added, and the cells were incubated for $3 \mathrm{~h}$. BrdU incorporation was quantified using the BrdU cell proliferation assay kit. The percentage of BrdU-positive VSMCs was determined. Data are presented as the mean \pm SE of three independent experiments. ${ }^{*} p<0.05$ vs. the no-oxLDL treatment group

VSMCs participate in the development of AS [21]. Abnormal VSMC proliferation and migration contribute to atherosclerotic plaque formation, restenosis after percutaneous transluminal angioplasty and accelerated arteriopathy after cardiac transplantation [22,23]. When chronic inflammation occurs in AS, arterial VSMCs become aberrantly regulated, leading to increased VSMC dedifferentiation and extracellular matrix formation in plaque areas [24]. Disturbances in hemodynamic forces could initiate a proinflammatory switch in the VSMC phenotype, even in the preclinical stages of AS [25]. Proinflammatory signals promote the further dedifferentiation of VSMCs in affected vessels and the propagation of pathological vascular remodeling [26, 27].

A number of studies have shown that SHP2 can promote VSMC proliferation and intimal hyperplasia [28, 29]. SHP2 was reported to be positively involved in the angiotensin II pathway, an important pathway involved in SMC proliferation [30]. SHP2 may act as an adaptor protein in the association of JAK2 with the $\mathrm{AT}_{1}$ receptor, thus facilitating Ang II-induced JAK2 phosphorylation and activation [31]. By enhancing the phosphorylation levels of Syk and p38 ${ }^{\mathrm{MAPK}}$, SHP2 facilitates the regulation of PDGF-BB-induced VSMC migration and neointima formation [32]. Induction by 

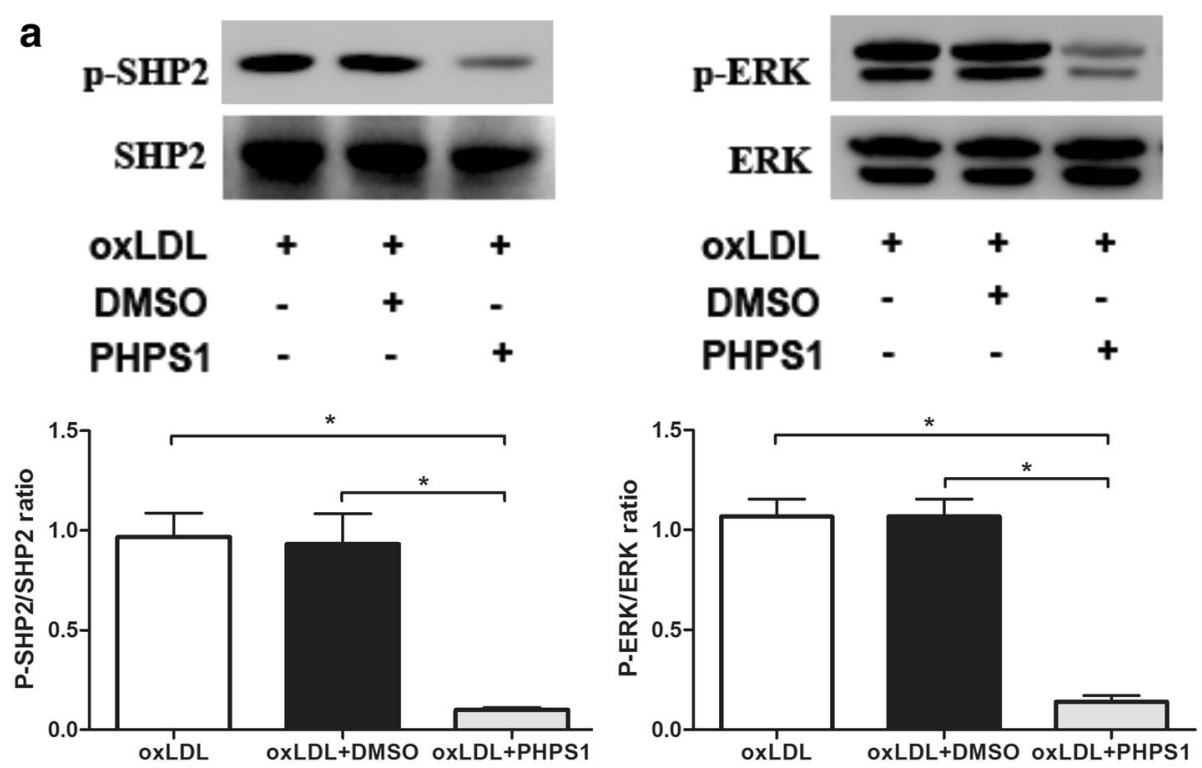

b

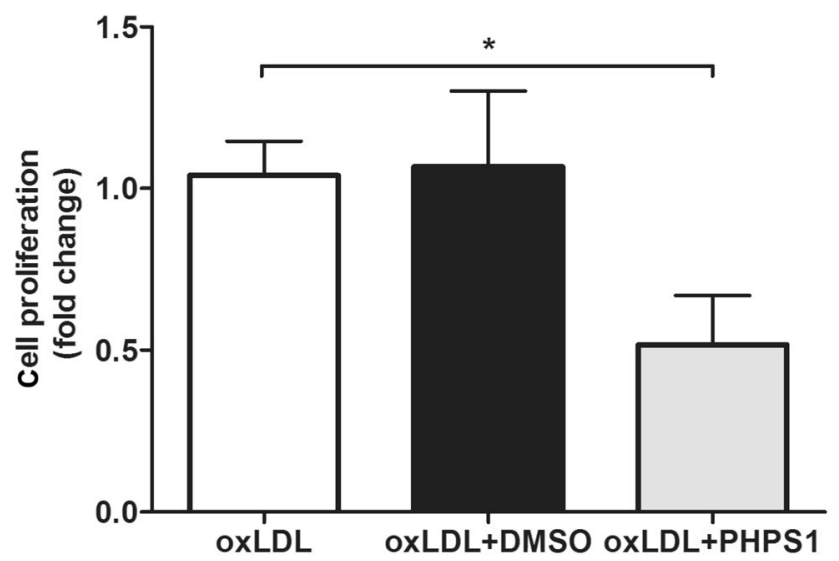

Fig. 6 a Protein expression levels of total SHP2, phosphorylated SHP2, total ERK and phosphorylated ERK in VSMCs. VSMCS were treated with PHPS1 or DMSO for $30 \mathrm{~min}$ and then with $100 \mu \mathrm{g} / \mathrm{ml}$ oxLDL for $10 \mathrm{~min}$. Data are presented as the mean $\pm \mathrm{SE}$. ${ }^{*} p<0.05 \mathrm{vs}$. the oxLDL group. $\mathbf{b}$ Effects of SHP2 on VSMC proliferation. After preincubation in the presence or absence of $10 \mu \mathrm{M}$ PHPS1 or an equal volume of DMSO for 30 min at $37^{\circ} \mathrm{C}$, cells were stimulated with oxLDL $(100 \mu \mathrm{g} / \mathrm{mL})$ for $24 \mathrm{~h}$. BrdU $(1 \mu \mathrm{mol} / \mathrm{L})$ was added, and the cells were incubated for $3 \mathrm{~h}$. BrdU incorporation was quantified using the BrdU cell proliferation assay kit. The percentage of BrdU-positive VSMCs was determined in the three groups. Compared with the other groups, the PHPS1 treatment group showed a decrease in the percentage of BrdU-positive VSMCs. ${ }^{*} p<0.05$ vs. the oxLDL group

extracellular stimuli such as FBS, platelet-derived growth factor or insulin-like growth factor-1 enhances SHP2 levels and BrdU uptake in SMCs, suggesting that SHP2 may accelerate VSMC proliferation [28].

Our in vivo experiments showed that inhibition of SHP2 by PHPS1 had a protective effect on AS development by reducing VSMC proliferation. To evaluate the effect of SHP2 on AS, $\mathrm{Ldll}^{-/-}$mice were fed a diet containing 1 . $25 \%$ cholesterol for 4 weeks. As a result, early plaques formed in the aortic root. Subcutaneous injection of PHPS1 significantly inhibited VSMC proliferation and intimal thickening during the development of AS. Moreover, PHPS1 treatment significantly inhibited ERK phosphorylation in the aortic wall; ERK is a key regulator of cell proliferation [19], indicating that PHPS1 may attenuate VSMC proliferation by regulating the activation of ERK signaling cascade. Our in vitro experiment also verified the inhibitory effect of SHP2 on VSMC proliferation.

Our in vitro data showed that oxLDL increased SHP2 and ERK phosphorylation and simultaneously enhanced VSMC proliferation. However, these responses were suppressed by treatment with the SHP2 inhibitor PHPS1. These results implied that SHP2 positively regulated VSMC proliferation in response to oxLDL by regulating 
ERK phosphorylation. SHP2 is reported to be involved in VSMC proliferation. OxLDL promotes the VSMC phenotypic switch from the contractile phenotype to the proinflammatory phenotype, which is associated with dedifferentiation and proliferation [33, 34]. In addition, OxLDL expedites the progression of AS through the accumulation of reactive oxygen species (ROS) and activation of the MAPK stress signaling cascade and stimulates the expression and secretion of ET-1 [35]. However, the relationship between SHP2 and oxLDL in VSMC proliferation remains unknown. This study showed that oxLDL stimulation further increased SHP2 phosphorylation, SHP2 activation by ERK phosphorylation promoted VSMC proliferation, and pretreatment with the SHP2 inhibitor PHPS1 inhibited the oxLDLinduced activation of SHP2 and VSMC proliferation. These results also indicated that SHP2 promoted VSMC proliferation via activation of the ERK signaling cascade.

\section{Conclusion}

The results of the present study suggest that the SHP2 inhibitor PHPS1 can inhibit VSMC proliferation by reducing the phosphorylation of ERK and suppressing activation of signaling cascade. PHPS1 is beneficial for delaying the development of AS, and it is a potential therapeutic target for cardiovascular diseases associated with vascular remodeling.

\section{Additional file}

Additional file 1: Figure S1. Ldlr $^{-/-}$mice fed with a diet containing $10 \%$ fat, $10 \%$ yolk powder and $1.25 \%$ cholesterol for 4 weeks were administered PHPS1 or vehicle at a dose of $3 \mathrm{mg} / \mathrm{kg}$ every day during the fourth week. Body weight (A); serum glucose levels (B); and TC, TG, LDL-C and HDL-C levels $(C)$ were measured. Data are reported as the mean \pm SE ( $n=10$ per group). ${ }^{*} p<0.05$ vs. the AS group. (TIF $20388 \mathrm{~kb}$ )

\section{Abbreviations}

AS: Atherosclerosis; BrdU: 5-bromo-2'-deoxyuridine; HDL-C: High-density lipoprotein cholesterol; LDL-C: Low-density lipoprotein cholesterol; OCT: Optimal cutting temperature; PBS: Phosphate-buffered saline; PHPS1: Phenylhydrazono pyrazolone sulfonate 1; PTK: Protein tyrosine kinase; PTP: Protein tyrosine phosphatase; PTPN11: Protein tyrosine phosphatase N 11; SHP2: Src homology 2 domain-containing protein tyrosine phosphatase 2; TC: Total cholesterol; TG: Triglyceride; VSMCs: Vascular smooth muscle cells

\section{Acknowledgements}

We would like to thank Yonghui He for his technical support. We gratefully acknowledge the support of the Pathology Department in our hospital.

\section{Availability of data and materials}

The raw data from the current study can be obtained from the corresponding author.

\section{Authors' contributions}

JSG contributed to study conception and design and data acquisition, analysis, and interpretation and drafted the manuscript. JC designed the study, coordinated the blinding, performed the statistical analysis, and assisted with data collection and manuscript editing. ZYC conducted the experiments and analyzed the data. All authors have critically revised the manuscript and approved the final manuscript.

\section{Ethics approval}

This experiment was approved by the Ethics Committee of the Second Military Medical University, China, and was conducted according with international guidelines for animal experiments. The animals were utilized and managed according to the guidelines of the National Institutes of Health (NIH Publication No. 85-23, revised 1996).

\section{Competing interests}

The authors declare that they have no competing interests.

\section{Publisher's Note}

Springer Nature remains neutral with regard to jurisdictional claims in published maps and institutional affiliations.

\section{Author details}

${ }^{1}$ Department of Cardiology, Shanghai Baoshan Hospital of Integrated Traditional Chinese and Western Medicine, Friendship Road 181, Baoshan District, Shanghai, China. ${ }^{2}$ Department of Cardiology, Shanghai Navy 411 Hospital, Shanghai, China.

Received: 15 November 2017 Accepted: 20 April 2018

Published online: 27 April 2018

\section{References}

1. Murray CJ, Barber RM, Foreman KJ, et al. Global, regional, and national disability-adjusted life years (DALYS) for 306 diseases and injuries and healthy life expectancy (HALE) for 188 countries, 1990-2013: quantifying the epidemiological transition. Lancet. 2015;386(10009):2145-91.

2. Ellulu MS, Patimah I, Khaza'ai $H$, et al. Atherosclerotic cardiovascular disease: a review of initiators and protective factors. Inflammopharmacology. 2016; 24(1):1-10.

3. Ley K, Miller Yl, Hedrick CC. Monocyte and macrophage dynamics during atherogenesis. Arterioscler Thromb Vasc Biol. 2011;31(7):1506-16.

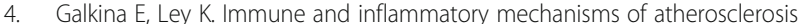
$\left(^{*}\right)$. Annu Rev Immunol. 2009;27:165-97.

5. Osman I, Poulose N, Ganapathy V, et al. High fructose-mediated attenuation of insulin receptor signaling does not affect PDGF-induced proliferative signaling in vascular smooth muscle cells. Eur J Pharmacol. 2016;791:703-10.

6. Lim S, Park S. Role of vascular smooth muscle cell in the inflammation of atherosclerosis. BMB Rep. 2014;47(1):1-7.

7. Gray K, Kumar S, Figg N, et al. Effects of DNA damage in smooth muscle cells in atherosclerosis. Circ Res. 2015;116(5):816-26.

8. Patarca R. Protein phosphorylation and dephosphorylation in physiologic and oncologic processes. Crit Rev Oncog. 1996;7(5-6):343-432.

9. Paz C, Cornejo Maciel F, Gorostizaga A, et al. Role of protein phosphorylation and tyrosine phosphatases in the adrenal regulation of steroid synthesis and mitochondrial function. Front Endocrinol (Lausanne). 2016;7:60

10. Fan $\mathrm{G}$, Aleem $\mathrm{S}$, Yang $\mathrm{M}$, et al. Protein-tyrosine phosphatase and kinase specificity in regulation of SRC and breast tumor kinase. J Biol Chem. 2015; 290(26):15934-47.

11. Chong ZZ, Maiese K. The Src homology 2 domain tyrosine phosphatases SHP-1 and SHP-2: diversified control of cell growth, inflammation, and injury. Histol Histopathol. 2007:22(11):1251-67.

12. Mannell H, Krotz F. SHP-2 regulates growth factor dependent vascular signalling and function. Mini Rev Med Chem. 2014;14(6):471-83.

13. Kamiya N, Kim HK, King PD. Regulation of bone and skeletal development by the SHP-2 protein tyrosine phosphatase. Bone. 2014:69:55-60.

14. Schramm C, Edwards MA, Krenz M. New approaches to prevent LEOPARD syndrome-associated cardiac hypertrophy by specifically targeting Shp2dependent signaling. J Biol Chem. 2013;288(25):18335-44.

15. Hellmuth K, Grosskopf S, Lum CT, et al. Specific inhibitors of the protein tyrosine phosphatase Shp2 identified by high-throughput docking. Proc Natl Acad Sci U S A. 2008;105(20):7275-80.

16. Abram CL, Lowell CA. Shp1 function in myeloid cells. J Leukoc Biol. 2017; 102(3):657-75

17. Panzhinskiy $\mathrm{E}$, Ren J, Nair S. Pharmacological inhibition of protein tyrosine phosphatase 1B: a promising strategy for the treatment of obesity and type 2 diabetes mellitus. Curr Med Chem. 2013;20(1875533X (Electronic)):2609-25. 
18. Li J, Kang Y, Wei L, et al. Tyrosine phosphatase Shp2 mediates the estrogen biological action in breast cancer via interaction with the estrogen extranuclear receptor. PLoS One. 2014;9(7):e102847.

19. Li FF, Shen J, Shen HJ, et al. Shp2 plays an important role in acute cigarette smoke-mediated lung inflammation. J Immunol. 2012;189(6):3159-67.

20. Matsuda M, Shimomura I, Sata M, et al. Role of adiponectin in preventing vascular stenosis. The missing link of adipo-vascular axis. J Biol Chem. 2002; 277(40):37487-91.

21. Zhang MJ, Zhou Y, Chen L, et al. SIRT1 improves VSMC functions in atherosclerosis. Prog Biophys Mol Biol. 2016;121(1):11-5.

22. Koga J, Aikawa M. Crosstalk between macrophages and smooth muscle cells in atherosclerotic vascular diseases. Vasc Pharmacol. 2012;57(1):24-8.

23. Johnson JL. Emerging regulators of vascular smooth muscle cell function in the development and progression of atherosclerosis. Cardiovasc Res. 2014; 103(4):452-60

24. Yin YW, Liao SQ, Zhang MJ, et al. TLR4-mediated inflammation promotes foam cell formation of vascular smooth muscle cell by upregulating ACAT1 expression. Cell Death Dis. 2014;5:e1574.

25. Chistiakov DA, Orekhov AN, Bobryshev YV. Vascular smooth muscle cell in atherosclerosis. Acta Physiol (Oxf). 2015;214(1):33-50.

26. Kiyan $Y$, Tkachuk S, Hilfiker-Kleiner $D$, et al. oxLDL induces inflammatory responses in vascular smooth muscle cells via urokinase receptor association with CD36 and TLR4. J Mol Cell Cardiol. 2014;66:72-82.

27. Hakimi M, Peters A, Becker A, et al. Inflammation-related induction of absent in melanoma 2 (AIM2) in vascular cells and atherosclerotic lesions suggests a role in vascular pathogenesis. J Vasc Surg. 2014:59(3):794-803.

28. Seki N, Hashimoto N, Suzuki Y, et al. Role of SRC homology 2-containing tyrosine phosphatase 2 on proliferation of rat smooth muscle cells. Arterioscler Thromb Vasc Biol. 2002;22(7):1081-5.

29. Kandadi MR, Stratton MS, Ren J. The role of Src homology 2 containing protein tyrosine phosphatase 2 in vascular smooth muscle cell migration and proliferation. Acta Pharmacol Sin. 2010;31(10):1277-83.

30. Marrero MB, Venema VJ, Ju H, et al. Regulation of angiotensin I-induced JAK2 tyrosine phosphorylation: roles of SHP-1 and SHP-2. Am J Phys. 1998; 275(5 Pt 1):C1216-23.

31. Godeny MD, Sayyah J, VonDerLinden D, et al. The N-terminal SH2 domain of the tyrosine phosphatase, SHP-2, is essential for Jak2-dependent signaling via the angiotensin II type AT1 receptor. Cell Signal. 2007;19(3):600-9.

32. Won KJ, Lee HM, Lee CK, et al. Protein tyrosine phosphatase SHP-2 is positively involved in platelet-derived growth factor-signaling in vascular neointima formation via the reactive oxygen species-related pathway. J Pharmacol Sci. 2011;115(2):164-75.

33. Makino J, Asai R, Hashimoto M, et al. Suppression of EC-SOD by oxLDL during vascular smooth muscle cell proliferation. J Cell Biochem. 2016; 117(11):2496-505.

34. Hwang JS, Ham SA, Yoo T, et al. Sirtuin 1 mediates the actions of peroxisome proliferator-activated receptor delta on the oxidized low-density lipoprotein-triggered migration and proliferation of vascular smooth muscle cells. Mol Pharmacol. 2016;90(5):522-9.

35. Xu H, Duan J, Ren J, et al. alpha-Zearalanol attenuates oxLDL-induced ET-1 gene expression, ET-1 secretion and redox-sensitive intracellular signaling activation in human umbilical vein endothelial cells. Toxicol Lett. 2008; 179(3):163-8.

\section{Ready to submit your research? Choose BMC and benefit from:}

- fast, convenient online submission

- thorough peer review by experienced researchers in your field

- rapid publication on acceptance

- support for research data, including large and complex data types

- gold Open Access which fosters wider collaboration and increased citations

- maximum visibility for your research: over $100 \mathrm{M}$ website views per year

At BMC, research is always in progress.

Learn more biomedcentral.com/submissions 